\title{
Highly relaxing gadolinium based MRI contrast agents responsive to $\mathrm{Mg}^{2+}$ sensing ${ }^{\mathrm{i}}$
}

\author{
Sabah Abada ${ }^{\mathrm{a}}$, Alexandre Lecointre ${ }^{\mathrm{a}}$, Mourad Elhabiri ${ }^{\mathrm{b}}$, David Esteban-Gómez ${ }^{\mathrm{c}}$, Carlos Platas- \\ Iglesias $^{c}$, Gaylord Tallec ${ }^{\mathrm{d}}$, Marinella Mazzanti ${ }^{\mathrm{d}}$ and Loïc J. Charbonnière ${ }^{\mathrm{a}^{*}}$ \\ ${ }^{a}$ Laboratoire d'Ingénierie Moléculaire Appliquée à l'Analyse, IPHC, UMR 7178 CNRS/UdS, ECPM 25 rue \\ Becquerel, 67087 Strasbourg Cedex 2, France \\ ${ }^{\mathrm{b}}$ Laboratoire de Chimie Bioorganique et Médicinale, UMR 7509 CNRS-UdS, ECPM, Université de Strasbourg, 25 \\ rue Becquerel, 67200 Strasbourg, France

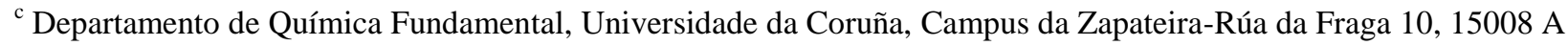 \\ Coruña, Spain \\ ${ }^{\mathrm{d}}$ Laboratoire de Reconnaissance Ionique et Chimie de Coordination, INAC, CEA Genoble, UMR-E 3 CEA-UJF, \\ 38054 Grenoble Cedex 9, France
}

Chemical Communications, volume 48, issue 34, pages 4085-4087, 28 April 2012

Received 2 February 2012, accepted 29 February 2012, first published 29 February 2012

\section{How to cite:}

Highly relaxing gadolinium based MRI contrast agents responsive to $\mathrm{Mg}^{2+}$ sensing. S. Abada, A. Lecointre, M. Elhabiri, D. Esteban-Gómez, C. Platas-Iglesias, G. Tallec, M. Mazzanti and L. J. Charbonnière, Chem. Commun., 2012, 48, 4085-4087. DOI: 10.1039/C2CC30757J.

\begin{abstract}
A Gd complex based on a polyphosphonated pyridyl ligand shows a very high stability in aqueous solution $\left(\log K_{\mathrm{EuL}}=25.7\right)$, a high relaxivity $\left(8.5 \mathrm{mM}^{-1} \mathrm{~s}^{-1}\right.$ at $25{ }^{\circ} \mathrm{C}$ and $\left.20 \mathrm{MHz}\right)$ and a marked and selective relaxivity enhancement $(37 \%)$ in the presence of $\mathrm{Mg}^{2+}$, opening interesting perspectives for the design of cation responsive contrast agents.
\end{abstract}

Keywords: MRI contrast agents; DFT calculations; gadolinium complexes; relaxivity; magnesium sensing

Stable $\mathrm{Gd}^{3+}$ complexes with polyaminocarboxylate ligands are commonly used as contrast agents in Magnetic Resonance Imaging (MRI). ${ }^{1}$ Contrast agents are paramagnetic molecules that enhance the image contrast by shortening the longitudinal and/or transversal relaxation times of protons of water molecules in the vicinity of the chelate.

Considering the efficiency of the commercially available gadolinium-based contrast agents, current efforts in this field of research are directed toward the fundamental understanding of the parameters governing the relaxivity in existing complexes or their derivatives, ${ }^{1}$ the preparation of nanoscopic scaffolds such as micelles ${ }^{2}$ or dendrimers, ${ }^{3}$ with enhanced relaxivities due to an increase of the rotational correlation time, or toward the design of smart probes responsive to the presence of enzymes, ${ }^{4}$ proteins ${ }^{5}$ or cations. ${ }^{6}$ Among these, smart probes for the detection of biologically relevant cations such as $\mathrm{Cu}^{2+}, \mathrm{Zn}^{2+}, \mathrm{Ca}^{2+}$ or $\mathrm{Mg}^{2+}$ are of particular interest for monitoring and imaging of the cellular flux of these cations. ${ }^{7}$

\footnotetext{
*1.charbonn@unistra.fr
} 
The essential prerequisites for efficient Gd-based relaxation agents are the highest possible relaxivity and high thermodynamic and kinetic stabilities that can be reached by the use of phosphonated functions. ${ }^{8} \mathrm{We}$ recently synthesized ligand $\mathbf{L H}_{8}$ (Scheme 1), ${ }^{9}$ based on a pyridyl moiety functionalized by two amino(methyl)bis(methylphosphonic) acid, which proved to be very efficient for the complexation of $\mathrm{Cu}^{2+9,10}$ thus indicating further potentialities for the coordination to lanthanide cations too. ${ }^{11}$

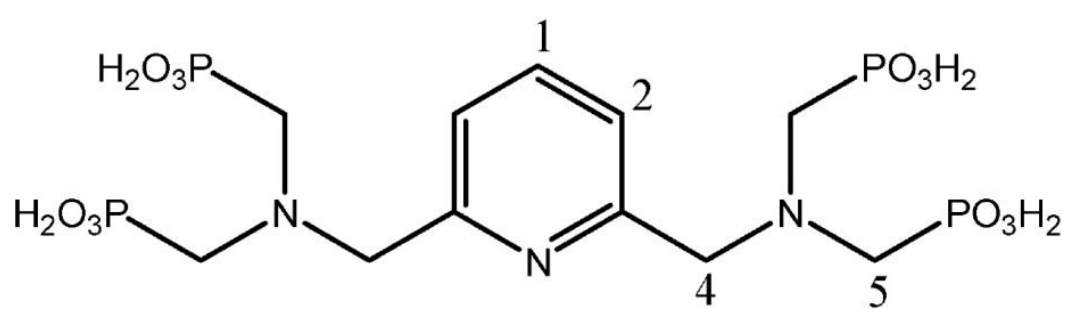

Scheme 1

In order to unravel the complexation behaviour of $\mathbf{L H}_{8}$ with lanthanide cations, spectrophotometric titration experiments (absorption and fluorescence) were first carried out by adding $\mathrm{Eu}^{3+}$ or $\mathrm{Tb}^{3+}$ salts into a solution of the ligand in buffered aqueous solutions (Fig. 1), keeping in mind that these cations are prone to lead to luminescent complexes thanks to the antenna effect. Monitoring the emission intensities at fixed wavelengths revealed a marked inflection point at a $1: 1 \mathrm{M}: \mathrm{L}$ ratio, followed by the formation of polynuclear species.

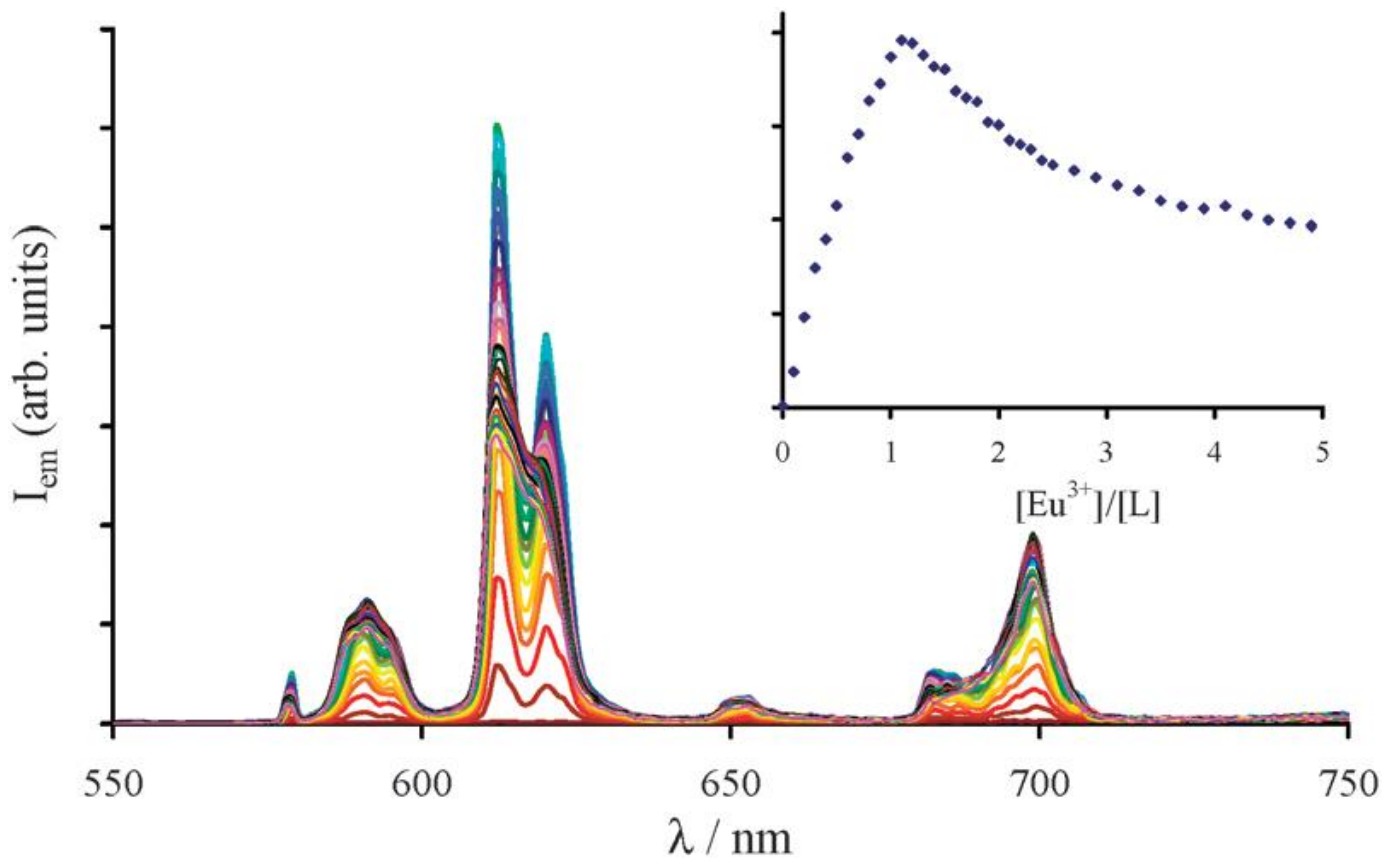

Fig. 1. Evolution of the emission intensity during the addition of $\mathrm{EuCl}_{3} \cdot 6 \mathrm{H}_{2} \mathrm{O}\left(8.2 \times 10^{-4} \mathrm{M}\right)$ to an aqueous solution of $\mathbf{L H}_{8}\left(8.5 \times 10^{-5} \mathrm{M}\right.$, in $0.01 \mathrm{M}$ Tris/ $\left.\mathrm{HCl}, \mathrm{pH}=7.0\right)$. Inset: Evolution of the emitted intensity at $620 \mathrm{~nm}$ as a function of the $[\mathrm{Eu}] /[\mathbf{L}]$ ratio. 
Potentiometric titrations were then performed on solutions containing equimolar amounts of the ligand and trivalent lanthanide salts $(\mathrm{Ln}=\mathrm{La}, \mathrm{Nd}, \mathrm{Tb}, \mathrm{Eu}, \mathrm{Nd}$ and $\mathrm{Lu}$ ). Despite the precipitation of the complexes at acidic $\mathrm{pH}$ for the heaviest lanthanides, it was possible to evaluate the thermodynamic stability constants (Table 1), using the previously reported protonation constants of the ligand ( $\mathrm{p} K_{\mathrm{a}}=11.21,10.29,8.04,6.49$, 5.53 and 4.19). ${ }^{9}$ Table 1 also provides the $\mathrm{pLn}$ values $\left(\mathrm{pLn}=-\log \left[\mathrm{Ln}^{3+}\right]_{\text {free }}\right.$ with $[\mathbf{L}]_{\mathrm{tot}}=10^{-5} \mathrm{M}$ and $[\mathrm{Ln}]_{\mathrm{tot}}=$ $10^{-6} \mathrm{M}$ at $\left.\mathrm{pH} 7.4\right)^{12}$ for $\mathbf{L}$, DOTA ${ }^{13}$ and DOTP, ${ }^{14}$ the phosphonated analogue of DOTA (full details of the potentiometric experiments are available in the ESI ${ }^{i}$ ).

Table 1. Stability constants $\left(\log K_{\mathrm{ML}}\right)$, successive protonation constants $\left(\log \boldsymbol{K}_{\mathbf{M L H}_{m}}\right)$ and pLn values of lanthanide complexes of $\mathbf{L}^{a, b}$

\begin{tabular}{lllllll}
\hline & $\mathrm{La}$ & $\mathrm{Nd}$ & $\mathrm{Eu}$ & $\mathrm{Tb}$ & $\mathrm{Er}$ & $\mathrm{Lu}$ \\
\hline $\log K_{\mathrm{ML}}$ & $25.5(4)$ & $27.1(3)$ & $25.7(3)$ & $29.7(6)$ & $29.7(1.0)$ & $29.3(4)$ \\
$\log K_{\mathrm{MLH}}$ & $9.4(4)$ & $8.8(3)$ & $9.4(3)$ & $7.6(7)$ & $7.8(1.0)$ & $7.4(6)$ \\
$\log K_{\mathrm{MLH}}$ & $7.3(6)$ & $6.6(4)$ & $7.5(4)$ & $c$ & $c$ & $c$ \\
$\log K_{\mathrm{M}(\mathrm{OH})}{ }^{b}$ & -8.83 & -8.20 & -7.78 & -7.66 & -7.54 & -7.29 \\
$\mathrm{pLn}_{\mathrm{L}}$ & 21.2 & 22.1 & 21.5 & 23.6 & 23.7 & 23.1 \\
$\mathrm{pLn}_{\text {DOTA }}$ & 17.8 & 17.8 & 18.4 & 19.6 & 19.6 & 20.3 \\
$\mathrm{pLn}_{\text {DOTP }}$ & 21.5 & 21.2 & 21.5 & 22.6 & 24.3 & 24.3 \\
\hline
\end{tabular}

${ }^{a}$ Solvent: water; $I=0.1 \mathrm{M}\left(\mathrm{NaClO}_{4}\right) ; T=25.0(2){ }^{\circ} \mathrm{C}$. Errors $=4 \sigma$ with $\sigma=$ standard deviation. $K_{\mathrm{ML}}=[\mathrm{ML}] /[\mathbf{L}][\mathrm{M}]$ and $K_{\mathrm{MLH}_{m}}=\left[\mathrm{MLH}_{m}\right] /\left[\mathrm{MLH}_{m-1}\right][\mathrm{H}]$. Charges have been omitted for the sake of clarity. ${ }^{b}$ The hydrolysis constants used for the processing of the potentiometric data on $\mathbf{L n}$ complexes with $\mathbf{L}$ have been taken from ref. $16 .{ }^{c} \mathrm{Not}$ determined because of precipitation of the Ln complexes below $\mathrm{pH} 6-6.5$.

As anticipated, the replacement of carboxylate functions by phosphonate ones led to a very large increase of the thermodynamic stability constants in the lanthanide series. The $\log K_{\mathrm{ML}}$ values obtained for the $\mathrm{Eu}$ and Tb complexes (Table 1) are several orders of magnitude higher than that reported for the Gd complex of $\mathbf{L}^{\prime}$, the analogue of $\mathbf{L}$ containing carboxylate functions instead of phosphonate ones $\left(\log K_{\mathrm{GdL}^{\prime}}=18.6, \mathrm{pGd}=\right.$ 17.5). ${ }^{15}$ Despite the non-macrocyclic structure of the ligand, the $\mathrm{pM}$ values reported in Table 1 clearly show that the complexes of $\mathbf{L}$ are more stable than the DOTA analogues, and almost as stable as those of DOTP, ${ }^{14}$ suggesting sufficient stability of the complexes for their use in biological media.

As previously observed for Ln complexes with ligands containing phosphonate groups, ${ }^{17}$ the potentiometric data revealed the formation of mono- and di-protonated species in solution (Table 1). Both the mono- and diprotonated forms of the complexes are expected to exist at physiological $\mathrm{pH}$. In the case of Eu, the relative abundance of non-protonated, mono-protonated and di-protonated forms are $0.4,44.1$ and $55.5 \%$ at $\mathrm{pH}=7.4$ $\left([\mathbf{L}]=[\mathrm{Eu}]=10^{-3} \mathrm{M}\right)$.

Considering the interest of stable hydrated Gd complexes as contrast agents for magnetic resonance imaging, the NMRD profile of the Gd complex was measured in water at $\mathrm{pH}=7.4$ and $25{ }^{\circ} \mathrm{C}$ (Fig. 2). The relaxivity of the $\mathrm{Gd}$ complex at $20 \mathrm{MHz}$ appeared to be very high $\left(r_{1}=8.5 \mathrm{mM}^{-1} \mathrm{~s}^{-1}\right.$ at $\left.25{ }^{\circ} \mathrm{C}\right)$ when compared to conventional monohydrated contrast agents such as $[\mathrm{Gd}(\mathrm{DOTA})]^{-}\left(r_{1}=4.2 \mathrm{mM}^{-1} \mathrm{~s}^{-1}\right)^{18}$ or $[\mathrm{Gd}(\mathrm{DTPA})]^{2-}$ $\left(r_{1}=4.3 \mathrm{mM}^{-1} \mathrm{~s}^{-1}\right){ }^{18}$ The NMRD profile (Fig. 2) indicated a behaviour typical of small complexes. ${ }^{1}$ The relaxivity determined at $25^{\circ} \mathrm{C}$ and $20 \mathrm{MHz}$ is very similar to those reported for Gd complexes with ligands containing phosphonate groups and one inner-sphere water molecule, ${ }^{19}$ which are endowed with relatively 
high relaxivities as a consequence of an important second-sphere contribution. Luminescence lifetimes of the europium complex were also measured in water $(0.57 \mathrm{~ms})$ and $\mathrm{D}_{2} \mathrm{O}(2.21 \mathrm{~ms})$ to determine the hydration number by Horrocks' method, ${ }^{20 \mathrm{a}}$ using refined coefficients obtained by Beeby et al. ${ }^{20 \mathrm{~b}}$ revealing a $q$ value of $1.0 \pm 0.1$.

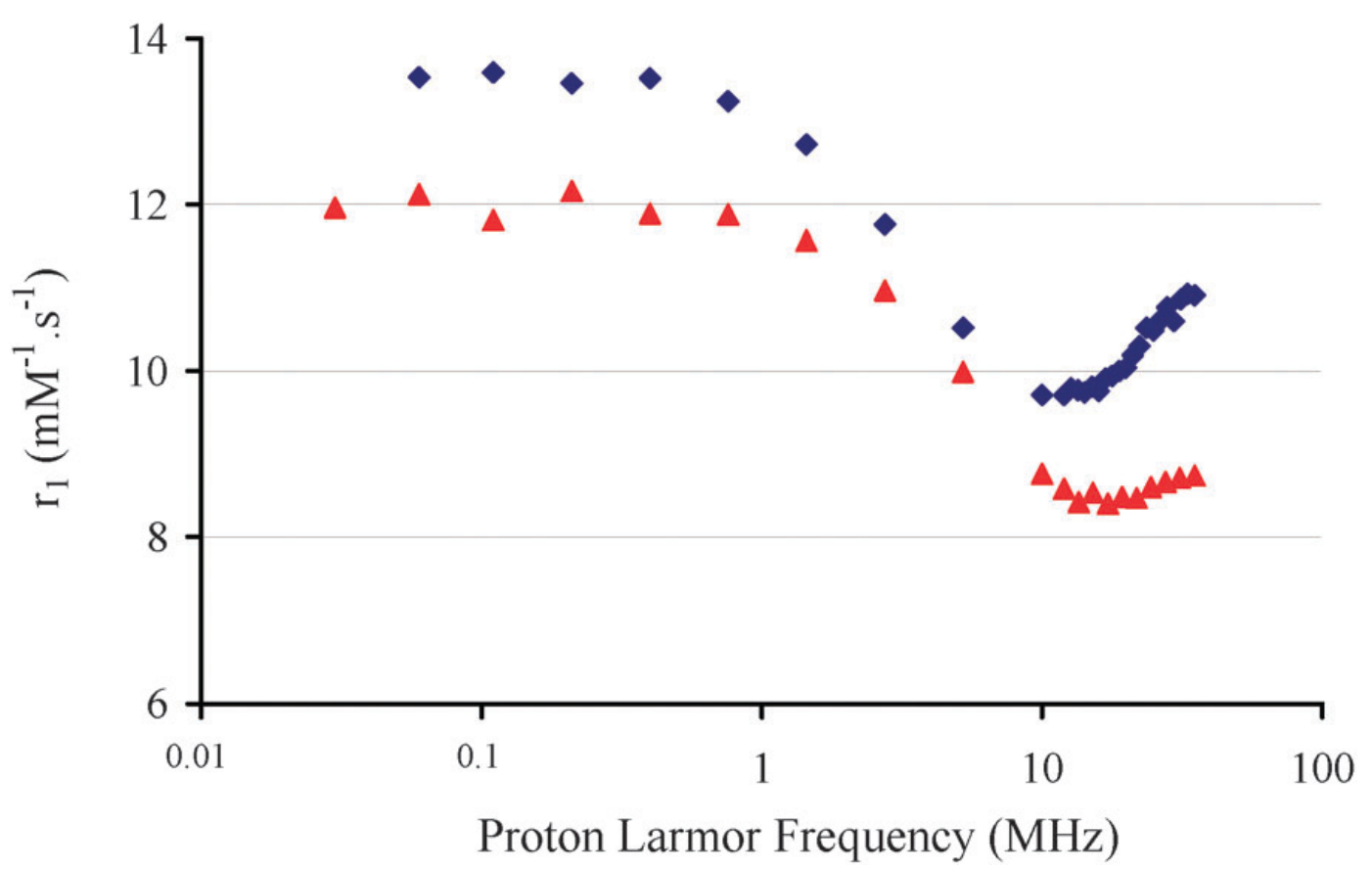

Fig. 2. NMRD profile of the Gd complex $\left(\mathrm{pH}=7.4,25^{\circ} \mathrm{C}\right)$ alone $(\mathbf{\Delta})$ and in the presence of 30 equivalents of $\mathrm{MgCl}_{2}(\bullet)$.

Considering the fruitless efforts for crystallizing the complexes, we turned our attention toward density functional theory (DFT) calculations at the B3LYP level (see ESI $^{\mathrm{i}}$ for full details), ${ }^{8}$ taking into account solvent effects (water) by using a polarizable continuum model (PCM). Fig. 3 represents the minimum energy conformation obtained for the $\left[\mathrm{Gd}\left(\mathrm{H}_{2} \mathbf{L}\right)\left(\mathrm{H}_{2} \mathrm{O}\right)\right]^{3-}$ system, which is expected to be the major form of the complex in solution at physiological $\mathrm{pH}$. According to our calculations the ligand provides an asymmetrical coordination of the metal ion due to the presence of an inner-sphere water molecule. The conformation adopted by the ligand in the complex implies the occurrence of two helicities: one associated with the layout of the methylenephosphonate arms (absolute configuration $\Delta$ or $\Lambda$ ), and the other to the four five-membered chelate rings formed by the binding of the $\mathrm{N}-\mathrm{CH}_{2}-\mathrm{P}-\mathrm{O}$ units (each of them showing absolute configuration $\delta$ or $\lambda){ }^{21}$ The minimum energy conformation calculated for $\left[\mathrm{Gd}\left(\mathrm{H}_{2} \mathbf{L}\right)\left(\mathrm{H}_{2} \mathrm{O}\right)\right]^{3-}$ corresponds to the $\Delta(\delta \delta \delta \delta)$ [or $\Lambda(\delta \delta \delta \delta)]$ form. Two of the methylenephosphonate groups are placed above and below the mean plane of the pyridyl fragment, while the remaining two methylenephosphonate groups lie close to that plane. The distance between Gd and the inner-sphere water molecule $(2.609 \AA)$ is ca. $0.1 \AA$ longer than those observed for different Gd polyaminocarboxylates, ${ }^{\mathrm{lb}}$ probably because the PCM solvation model does not take into account specific interactions between the inner-sphere water molecules and the second hydration sphere of the complex.

The conformation adopted by the ligand in the complex according to our DFT calculations is in agreement with the NMR spectra recorded for the diamagnetic Lu complex (Fig. 3). The ${ }^{1} \mathrm{H}$ NMR spectrum recorded at $278 \mathrm{~K}$ shows an $\mathrm{AB}$ spin system for protons $\mathrm{H} 4$ at 4.21 and $3.61 \mathrm{ppm}\left({ }^{2} J=15.0 \mathrm{~Hz}\right)$ and 4 distinct signals for the methylene protons adjacent to the phosphonate functions. This points to an overall $C_{2}$ symmetry of 
the complex in solution with different signals for the in plane (ip) and out-of-plane (op) methylenephosphonate groups. This was further confirmed by the presence of two peaks with the same intensity in the ${ }^{31} \mathrm{P}-\mathrm{NMR}$ spectrum at 18.9 and $21.6 \mathrm{ppm}$.

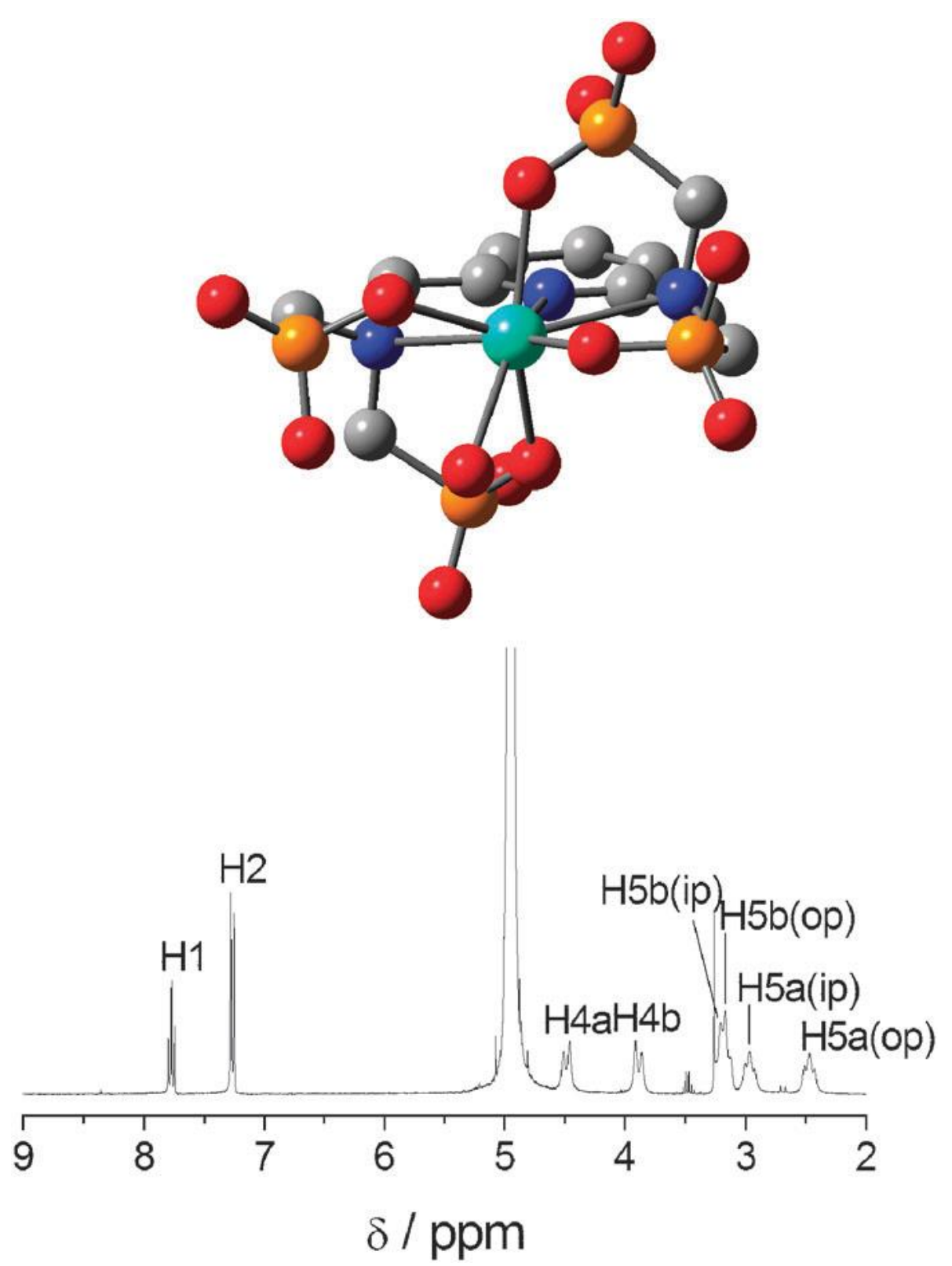

Fig. 3. (top) Minimum energy conformation obtained from DFT calculations (B3LYP) in aqueous solution for the $\left[\mathrm{Gd}\left(\mathrm{H}_{2} \mathbf{L}\right)\left(\mathrm{H}_{2} \mathrm{O}\right)\right]^{3-}$ system $\left(d_{\mathrm{Gd}-\mathrm{Npyr}}=2.714 \AA\right.$ 的 $d_{\mathrm{Gd}-\mathrm{Nalk}}=2.771$ and $2.824 \AA$ and $\left.d_{\mathrm{Gd}-\mathrm{O}}=2.29-2.42 \AA\right)$. (bottom) ${ }^{1} \mathrm{H}$ NMR spectrum of the Lu complex of $\mathbf{L}$ recorded in $\mathrm{D}_{2} \mathrm{O}$ solution at $278 \mathrm{~K}(\mathrm{pD}=10.5)$; see Scheme 1 for labeling. Ip and op refer to in-plane and out-of-plane methylenephosphonate groups, respectively.

Considering the negative charge of the Gd complex at $\mathrm{pH}$ close to neutrality, its possible interactions with cations were investigated by monitoring the changes of the relaxivity in the presence of $\mathrm{Ca}^{2+}$ and $_{\mathrm{Mg}^{2+}}$. In the presence of up to 200 equivalents of $\mathrm{CaCl}_{2}$, almost no impact was observed on the relaxivity of the complex which varied from 8.78 to $8.48 \mathrm{mM}^{-1} \mathrm{~s}^{-1}\left(\mathrm{pH}=7.4,25{ }^{\circ} \mathrm{C}, 200 \mathrm{MHz}\right)$ without and with $\mathrm{Ca}^{2+}$. In contrast, addition of $\mathrm{MgCl}_{2}$ resulted in a $37 \%$ enhancement of the relaxivity (see Fig. S1, ESI ${ }^{\mathrm{i}}$ ), rising up to $12.0 \mathrm{mM}^{-1} \mathrm{~s}^{-1}$ in the same conditions. 
The absence of free gadolinium was checked in all samples by the xylenol orange test, ruling out the possibility of gadolinium release in the presence of magnesium. The NMRD profile of the Gd complex in the presence of 30 equivalents of $\mathrm{MgCl}_{2}$ (Fig. 2) confirmed the large enhancement of the relaxivity at all frequencies, but also revealed a larger enhancement at high frequencies, generally associated to the increase of the rotational tumbling time of the complex. ${ }^{1}$ This behaviour is likely related to the formation of polynuclear clusters as often observed with phosphonate based lanthanide complexes. ${ }^{22}$

In conclusion, the interaction of the non-macrocyclic ligand $\mathbf{L}$ with lanthanide complexes led to the formation of very stable [ $\mathbf{L n L}]$ complexes, which displayed a high relaxivity for the Gd complex. In addition, [GdL] showed a marked and selective relaxivity enhancement in the presence of $\mathrm{Mg}^{2+}$ and no changes in the presence of $\mathrm{Ca}^{2+}$. Such simple polyphosphonated scaffolds may provide a large interest in the design of new $\mathrm{Gd}$ based complexes for magnetic resonance imaging and our current efforts are devoted toward the deep understanding of their properties and the preparation of bifunctional chelatorsfor labelling of biomaterial with this kind of ligand.

\section{References}

1. (a) A. E. Merbach and E. Toth, The Chemistry of Contrast Agents in Medical Magnetic Resonance Imaging, Wiley, London, 2001; (b) P. Caravan, J. J. Ellison, T. J. McMurry and R. B. Lauffer, Chem. Rev., 1999, 99, 2293-2352.

2. (a) S. Aime, D. Delli Castelli, S. Geninatti Crich, E. Gianolio and E. Terreno, Acc. Chem. Res., 2009, 42, 822-831; (b) A. Accardoa, D. Tesauroa, L. Alojb, C. Pedonea and G. Morelli, Coord. Chem. Rev., 2009, 253, 2193-2213.

3. W. C. Floyd, P. J. Klemm, D. E. Smiles, A. C. Kohlgruber, V. C. Pierre, J. L. Mynar, J.-M. J. Fréchet and K. N. Raymond, J. Am. Chem. Soc., 2011, 133, 2390-2393.

4. T. Chauvin, P. Durand, M. Bernier, H. Meudal, B.-T. Doan, F. Noury, B. Badet, J.-C. Beloeil and E. Toth, Angew. Chem., Int. Ed., 2008, 47, 4370-4372.

5. P. Caravan, Acc. Chem. Res., 2009, 42, 851-862.

6. (a) R. Trokowski, J. Ren, F. K. Kalman and A. D. Sherry, Angew. Chem., Int. Ed., 2005, 44, 69206923; (b) E. L. Que, E. Gianolio, S. L. Baker, A. P. Wong, S. Aime and C. J. Chang, J. Am. Chem. Soc., 2009, 131, 8527-8536.

7. (a) V. Kubicek, T. Vitha, J. Kotek, P. Hermann, L. Vander Elst, R. N. Müller, I. Lukes and J. A. Peters, Contrast Media Mol. Imaging, 2010, 5, 294-296; (b) G. Angelovski and I. Mamedov, Curr. Inorg. Chem., 2011, 1, 76-90.

8. K. Nchimi Nono, A. Lecointre, M. Regueiro-Figueroa, C. Platas-Iglesias and L. Charbonnière, Inorg. Chem., 2011, 50, 1689-1697.

9. S. Abada, A. Lecointre, M. Elhabiri and L. Charbonnière, J. Chem. Soc., Dalton Trans., 2010, 39, 9055-9062.

10. S. Abada, A. Lecointre, I. Déchamps-Olivier, C. Platas-Iglesias, C. Christine, M. Elhabiri and L. Charbonnière, Radiochim. Acta, 2011, 99, 663-678.

11. I. Lukes, J. Kotek, P. Vojtisek and P. Hermann, Coord. Chem. Rev., 2001, 216-217, 287. 
12. W. R. Harris, C. J. Carrano and K. N. Raymond, J. Am. Chem. Soc., 1979, 101, 2213-2214.

13. W. P. Cacheris, S. K. Nickle and A. D. Sherry, Inorg. Chem., 1987, 26, 958-960.

14. A. D. Sherry, J. Ren, J. Huskens, E. Brücher, É. Tóth, C. F. C. G. Geraldes, M. M. C. A. Castro and W. P. Cacheris, Inorg. Chem., 1996, 35, 4604-4612.

15. L. Pellegatti, J. Zhang, B. Drahos, S. Villette, F. Suzenet, G. Guillaumet, S. Petoud and E. Toth, Chem. Commun., 2008, 6591-6593.

16. G. D. Klungness and R. H. Byrne, Polyhedron, 2000, 19, 99-107.

17. M. Mato-Iglesias, E. Valgo, C. Platas-Iglesias, E. Tóth, A. de Blas and T. Rodríguez-Blas, Dalton Trans., 2006, 5404-5415.

18. S. Aime, M. Botta, M. Panero, M. Grandi and F. Uggeri, Magn. Reson. Chem., 1991, 29, 923-927.

19. (a) J. Kotek, P. Lebduskova, P. Hermann, L. Vander Elst, R. N. Muller, C. F. G. C. Geraldes, T. Maschmeyer, I. Lukes and J. A. Peters, Chem.-Eur. J., 2003, 9, 5899-5915; (b) S. Aime, E. Gianolio, D. Corpillo, M. Cavalloti, M. Palmesano, M. Sist, G. B. Giovenzana and R. Pagliarin, Helv. Chim. Acta, 2003, 86, 615-632.

20. (a) W. D. W. Horrocks and D. R. Sudnick, J. Am. Chem. Soc., 1979, 101, 334-340; (b) A. Beeby, I. M. Clarkson, R. S. Dickins, S. Faulkner, D. Parker, L. Royle, A. S. de Sousa, J. A. G. Williams and M. Woods, J. Chem. Soc., Perkin Trans. 2, 1999, 493-503.

21. (a) E. J. Corey and J. C. Bailar, J. Am. Chem. Soc., 1959, 81, 2620-2629; (b) J. K. Beattie, Acc. Chem. Res., 1971, 4, 253-259.

22. S. Comby, R. Scopelitti, D. Imbert, L. Charbonnière, R. Ziessel and J.-C. G. Bünzli, Inorg. Chem., 2006, 45, 3158-3160.

\footnotetext{
${ }^{\mathrm{i}}$ Electronic supplementary information (ESI) available: Details on potentiometric, spectrophotometric and relaxometric
}

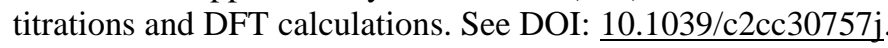

